\title{
Women's decision-making autonomy and its relationship with child feeding practices and postnatal growth
}

\author{
Mahama Saaka \\ School of Allied Health Sciences, University for Development Studies, P.O. Box TL 1883, Tamale, Ghana \\ (Received 31 March 2020 - Final revision received 24 June 2020 - Accepted 22 July 2020)
}

Journal of Nutritional Science (2020), vol. 9, e38, page 1 of 13

doi:10.1017/jns.2020.30

Abstract

Childhood stunting remains a global public health concern. Little has been documented on the effect of women's decision-making autonomy on child growth in settings where decision-making at the household and community levels is largely dominated by men. To assess the relationship between maternal autonomy and child growth, we analysed data from a cross-sectional study of 422 mothers and their youngest child aged 6-24 months in the Bawku West District of Ghana. The dimensions of women's autonomy measured were decision-making power, freedom of mobility and financial autonomy. We then compared how each dimension was associated with the likelihood of stunting and wasting. The important predictors of child growth and dietary intake as measured by the mean length-for-age Z-score (LAZ) and minimum acceptable (MAD) diet, respectively, were determined using multivariable regression models. The overall composite index of women autonomy (CIWA) showed that $52 \cdot 8 \%$ of women were of high autonomy and half of them had higher autonomy regarding their own and their children's health. After adjusting (multiple regression analysis) for potential confounders, the mean LAZ of children born to women of high autonomy was significantly higher than LAZ of children born to women of low autonomy $(\beta=0 \cdot 132 ; 95 \%$ CI $0 \cdot 19,0 \cdot 95 ; P$ $=0 \cdot 004)$. Similarly, high women's autonomy was a significant independent predictor of meeting MAD (AOR $=1 \cdot 59 ;$ CI 1.09, 2.34). Of all, the dimensions of women's autonomy measured in this study, health care autonomy better predicted child growth and dietary intake. Based on the findings, nutrition policies and interventions that enhance women's decision-making autonomy could have a positive impact on child growth outcomes.

Key words: Women's autonomy: Health care decision-making: Dietary diversity: Child growth outcomes: Ghana

\section{Introduction}

Childhood stunting (height-for-age $Z$-scores below -2) remains a global public health concern. It is well documented that malnutrition delays growth and development and also exposes individuals to increased risk of acquiring an infectious disease ${ }^{(1)}$ especially in developing countries, where malnutrition contributes to over 50 $\%$ of childhood deaths ${ }^{(2)}$. The problem of child malnutrition is multifaceted and one potential area that holds promise in the search for solutions to this is the enhancement of decision-making autonomy of the woman. Women's autonomy has been variously defined and measured. As in similar other studies, autonomy is defined as the ability to make decisions on one's own, to control one's own body and to determine how resources will be used, without needing to consult with or ask permission from another person ${ }^{(3)}$. Defined this way, women's autonomy denotes control, which is likely an important factor that influences childcare, and may improve nutritional outcomes ${ }^{(4,5)}$. A better understanding of how women's autonomy impacts on child nutritional status will hopefully project it as a vital public health intervention in developing nations to facilitate progress towards accomplishing many of the Sustainable Development Goals (SDGs).

Women in every society contribute significantly to the upkeep of family members but are often constrained in some societies in taking decisions that affect their health. It has been reported that more than half of the women in Africa, Asia, Latin America and the Caribbean have no say in everyday household decisions, like making large household purchases for daily need, visit to family or relatives on

Corresponding author: Mahama Saaka, email: mmsaaka@gmail.com

(C) The Author(s), 2020. Published by Cambridge University Press on behalf of The Nutrition Society. This is an Open Access article, distributed under the terms of the Creative Commons Attribution licence (http://creativecommons.org/licenses/by/4.0/), which permits unrestricted re-use, distribution, and reproduction in any medium, provided the original work is properly cited. 
decisions regarding their health care ${ }^{(6)}$. A woman's degree of autonomy in the household may have an impact on her ability to make decisions in the best interest of children's health or may limit her ability to direct household resources to her children. It has also been reported that low empowerment status curtails women's ability to access health care ${ }^{(7)}$ and that women who have lower autonomy within their household suffer from undernutrition themselves ${ }^{(8,9)}$.

Emerging available evidence suggests a positive effect of women's autonomy on child nutritional outcomes in a number of settings, including Pakistan, Bangladesh, India and Tanzania ${ }^{(4,10-12)}$. However, some other studies conducted elsewhere including Kenya and Nepal showed that maternal autonomy has a limited or no influence on child nutrition measures ${ }^{(13-16)}$. The literature is, therefore, inconclusive on the role of maternal autonomy and its relationship with nutrition being complex ${ }^{(4,17)}$.

From the foregoing, it appears the role of women's autonomy in influencing childcare and nutritional outcomes may be context-specific and its relevance in some societies warrants further investigation.

To effectively fight malnutrition, there is an urgent need to identify all the key potential determinants. Though a lot of studies on the relation between women's autonomy on child nutritional status have been conducted, there still remain unanswered questions. For example, the number of studies measuring separate dimensions of autonomy in one study is fairly limited making it difficult to infer any trends ${ }^{(4)}$. Therefore, more research is needed to clarify whether different dimensions do have differing impacts on child nutrition as this will pave the way to focus on relevant public health interventions that will enhance the most important aspects of women's autonomy. Furthermore, the role of the child's age on the effect of women's autonomy on child nutritional status is also less investigated. Could child's age interact or moderate the effect of women's autonomy on child nutrition?

Furthermore, a few of the past studies on this subject matter have measured all three World Health Organization (WHO) child growth outcomes (weight-for-age, weight-for-height and height-for-age). Measuring all three nutritional outcomes would improve comparability among studies and ensure that important associations of autonomy on child nutritional status are not missed ${ }^{(4)}$.

This present study sought to provide answers to these knowledge gaps in this analytical cross-sectional study conducted in the Bawku West District of Ghana, where malnutrition is high and decision-making at the household and community levels is largely dominated by men. Women's autonomy in the control of resources is an essential ingredient for adequate health care. We, therefore, hypothesized that women who are more autonomous would be able to allocate time and resources towards her own and children's well-being.

\section{Methods}

\section{Study setting}

The study was conducted in the Bawku West District which is one of the thirteen districts and municipalities in the Upper
East Region of Ghana. The district was created in 1988 under the local government system by Legislative Instrument (LI) 1442. The district covers an area of approximately $1070 \mathrm{~km}^{2}$, which constitutes about $12 \%$ of the total land area of the Upper East Region.

The population of the Bawku West District, according to the 2010 Population and Housing Census, is 94,034 representing $9.0 \%$ of the region's total population. Males constitute 48 $\%$ and females represent $52 \%$ of the district's population. About ninety $(90.8 \%)$ percentage of the population is rural.

The main economic activity of the people is agriculture (74.2\%) involving crop production, livestock and fish farming. Some of the crops cultivated are maize, sorghum, millet, groundnut, cowpea, soybeans, yam, rice as well as cassava. The major animals reared include cattle, sheep, goats, fowls, guinea fowls and birds are practically reared in every home.

\section{Study design, population and sampling procedure}

This study used a community-based analytical cross-sectional design. Using the formula for estimating sample size of single proportions with a $95 \%$ confidence level (CI) and an assumed regional prevalence of $50 \%$ of women that are autonomous and a margin of error of 0.05 , making $10 \%$ provision for dropouts in the study, the sample size was calculated to be 422 .

Mothers/primary caregivers and their children under 2 years participated in the study. Mother-child pairs from each household were eligible for inclusion in the study. We used a twostage sampling procedure which was done by first using simple random sampling to select 25 communities from a list of communities from four sub-sections across the Zebilla District. The primary sampling units in the selected clusters were households. The minimum sample required for each cluster was sixteen households which were selected using a systematic sampling technique. In households with more than one eligible child, one was chosen at random to participate in the study.

\section{Data collection}

Quantitative data were collected using structured questionnaire through face-to-face interviews during house-to-house visits. The questionnaire comprised socio-demographic characteristics of mothers/caregivers, autonomy level of mothers and anthropometric measurements of mother and child.

Independent and dependent variables and their measurement. The main explanatory variable in this study was women's autonomy. There were two main outcome variables. The first was postnatal growth which was defined quantitatively as length-for-age $Z$-score (LAZ) and weight-for-length $Z$-score (WLH). The categorical equivalents of these as binary variables are stunted/not stunted and wasted/ not wasted, respectively. A child was classified as stunted if HAZ is below -2 SD below the population median, wasted if WHZ is below -2 SD below the population median and underweight as weight-for-age below $-2 \mathrm{SD}$ from the median of the WHO Child Growth Standards ${ }^{(18)}$. 
The other outcome variable was child dietary intake which was measured qualitatively in terms proportion of children aged 6-23 months who received minimum acceptable dietary intake and postnatal growth of children aged 6-24 months.

Other confounders included (1) age and gender of the child; (2) maternal education, and utilisation of prenatal care and (3) household wealth status and maternal age. The main independent and dependent variables were measured as follows.

Measurement of women's autonomy. Of the several dimensions of women's autonomy described in the literature, four were assessed in this study: health care autonomy, general maternal household decision-making autonomy, movement autonomy and financial autonomy.

The index for general decision-making autonomy was composed of five questions, including the following:

(1) Who makes the decision if you need to buy clothes for yourself?

(2) Who makes the decision if you need to buy large household items/furniture?

(3) Who makes the decision when your children have stationeries/school needs to be addressed?

(4) Who makes the decision on how to spend the family's income?

(5) Who in your household usually has the final say on having another child?

The responses to the questions were scored as follows: two points for decisions made by the woman; one point by decisions made jointly by both the woman and her husband; zero for all of the decisions taken by others.

Health care autonomy was defined as women's autonomy over her own or child's health care and was measured using three questions as follows:

(1) Who makes the decision whether a child is sick enough to go for treatment?

(2) Who in your household usually has the final say on your own health care?

(3) If you are ill and need to see a doctor, do you first have to ask someone's permission?

Financial autonomy was related to evidence of women's control over financial resources. It was composed of three items: Whether a woman could spend her earn money without consulting anyone?; Who decides how family income is spent?; Who makes the decision whether a woman should work outside of the home?

The mobility/social autonomy dimension measured a mother's freedom of movement through her ability to independently travel to various places, attend social events or visit family and friends. The index of freedom of movement consisted of five items pertaining to whether women are usually allowed to go to some places on her own: just outside her house or compound, local market to buy things, local health centre or doctor, neighbourhood for recreation and home of relatives or friends in the neighbourhood ${ }^{(19)}$. The responses were scored as 1 (no permission required) and 0 (yes permission always required).
An overall composite index of women autonomy (CIWA), combining the four dimensions was also calculated. Two categories (i.e. low and high) of the individual components and the CIWA were created on the basis of the average value of each variable in the study sample. The women scoring less than the average score were put in the low autonomy category and women of at least the average score were categorised as high autonomy.

\section{Anthropometric assessment}

Anthropometric measurements of length/height and weight were taken by two people, one who was primarily responsible for positioning the child and reading the measurement and another who made sure the position was correct and recorded the measurement. All measurements were recorded to one decimal place.

The length measurement was taken with the child lying correctly in an infantometer with the movable end as a foot piece. Length measurements were taken for children below 2 years who could not stand properly for a correct height measurement. Where the length was measured for children above 2 years, $0.7 \mathrm{~cm}$ was subtracted from the measurement to convert it to height. Height measurement was taken for children above 2 years using an infantometer and mothers using a microtoise. Height was measured when subjects were standing straight with feet together, buttocks and lower back touching the wall (infantometer), subject looking straight ahead without footwear and long hair well-positioned. Weight measurement was taken for mothers and children on the scale with minimal movements of subjects on the scale and minimal clothing.

We assessed nutritional status outcomes including length-forage (LAZ), weight-for-age (WAZ) and weight-for-length or (WLZ) calculated using the WHO 2005 growth standards ${ }^{(18)}$.

Age determination. Dates of birth for children in this study were taken from their health records booklets and other relevant sources available. Mothers' ages were taken from documents such as National Voter's ID cards, Health Insurance ID cards, Mother's Pregnancy Antenatal Booklets and estimated age for others based on the age of their firstborn and other locally important calendar events such as the 1982 famine in Ghana.

Measurement of infant and young child feeding (IYCF) practices. One round of quantitative 24-hour dietary recall for the previous day was used to estimate the dietary practices of children ${ }^{(20)}$. The specific IYCF indicators assessed were timely initiation of breast feeding, timely complementary feeding, minimum dietary diversity, minimum meal frequency and minimum acceptable diet (MAD), appropriate complementary feeding and Infant and child feeding index (ICFI), a composite index which measures complete feeding practices for infants and young children.

The overall ICFI computed comprised feeding practices, including currently breast-feeding status, timely initiation of breast feeding within 1 hour, avoidance of prelacteal feeding, 
avoidance of bottle feeding, introduction of complementary foods at 6 months, minimum meal frequency, minimum dietary diversity and feeding child with colostrum.

Minimum dietary diversity is defined by the $\mathrm{WHO}$ as the proportion of children who received foods from at least four out of seven food groups. Minimum meal frequency was defined as children 6-36 months of age who received solid, semi-solid or soft foods a minimum number of times in the previous day. The minimum required frequency varied by child age and breast-feeding status (6-8 months is two times, 9-11 months is three times and 12-23 months is three times). MAD is a combined indicator of both minimum dietary diversity and minimum meal frequency.

The seven foods groups used for the assessment of IYCF practices were (1) grains, roots and tubers; (2) legumes and nuts; (3) dairy products; (4) flesh foods; (5) eggs; (6) vitamin A-rich fruits and vegetables and (7) other fruits and vegetables.

Assessment of socio-economic status. A household wealth index based on household assets and housing quality was used as a proxy indicator for socio-economic status (SES) of households. Principal Component Analysis (PCA) was used to determine household wealth index from information collected on housing quality (floor, walls and roof material), source of drinking water, type of toilet facility, the presence of electricity, type of cooking fuel, and ownership of modern household durable goods and livestock (e.g. bicycle, television, radio, motorcycle, sewing machine, telephone, cars, refrigerator, mattress, bed, computer and mobile phone $)^{(21-24)}$. The first principal component which explains as much of the variability in wealth index as possible was used to classify respondents with respect to SES. The different assumptions of PCA that data must meet for PCA to give valid results were as follows:

(1) The variables were measured at the continuous or ordinal levels.

(2) The variables were closely related and so there was some amount of linear relationship between the variables. The reason for this assumption is that a PCA is based on Pearson correlation coefficients, and as such, there needs to be a linear relationship between the variables.

(3) There was sampling adequacy, which simply means that for PCA to produce a reliable result, large enough sample sizes are required. The 422 sample size used was more than the recommended minimum sample size of 150 .

\section{Statistical data analysis}

The quantitative data were analysed using IBM SPSS statistic version 22 (SPSS Inc., Chicago, Illinois). WHO Anthro software version 3.2.2 was used to convert anthropometric measurements to $Z$-scores which were then transferred to SPSS software for further analyses. Anthropometric $Z$-scores of height-for-age (HAZ) and weight-for-height (WHZ) were determined. Before testing for associations between independent and the dependent variables, the data were cleaned. The raw data were checked for accuracy and consistency according to a standard procedure including double entry and running a frequency distribution on each of the variables in SPSS software. The main aim was to look for data entry errors and patterns to determine the primary sources of data inaccuracy. For example, if a variable with a Likert scale ranging from 1 to 5, all of your values should be in this range. The anthropometric data were checked for values outside the expected ranges. $Z$-scores which were outside the WHO flags: WHZ -5 to 5 ; HAZ -6 to 6 and WAZ -6 to 5 were excluded from the data set.

Bivariable and multivariable analyses were performed to identify the determinants of stunting, overweight and wasting. Bivariable analyses were performed using Chi-square $\left(\chi^{2}\right)$ tests and some cases Fisher's Exact Test. All explanatory variables that showed statistically significant association in the bivariable analysis with the outcome variables were entered to a multivariable linear regression model to identify independent factors associated with length-for-age $Z$-scores. Before running the regression, Pearson correlation analysis was run to eliminate highly correlated independent variables that had a correlation coefficient greater than $0 \cdot 70^{(25)}$.

The important predictors of stunting and MAD were determined using binary logistic regression. Odds ratios (ORs) along with CIs were used to determine the association between predictor variables and outcome measures, considering significant association at $\alpha<0 \cdot 05$.

\section{Ethical considerations}

The study protocol was approved by the School of Allied Health Sciences, University for Development Studies. Informed consent was also obtained from study participants after needed information and explanation. In situations, where the respondent could not write or read, verbal informed consent was sought from all the study participants before the commencement of any interview.

\section{Results}

Socio-demographic characteristics of the study sample. The mean $(+\mathrm{SD})$ age of mothers was $31 \cdot 83(6 \cdot 83)$ years with a range of 18-65 years. The mean (+SD) age of children was $14 \cdot 17$ $(8 \cdot 007)$ months. The sample comprised 55.9\% male children and the majority of the children were in the age group 12-23 months. Many of the respondents $(49.5 \%)$ had no formal education at all and $86.3 \%$ were married. Farming $(30.8 \%)$ was the commonest occupation among the mothers (Table 1).

Nutritional status of mothers and children aged 6-24 months. The prevalence of stunting, wasting and underweight in the study sample was $27 \cdot 7,7 \cdot 8$ and $9.2 \%$, respectively (Table 2). Out of 422 mothers, $4.5 \%$ of them having heights less than $150 \mathrm{~cm}$, while $6.9 \%$ were less than $18.5 \mathrm{~kg} / \mathrm{m}^{2}$.

The mean $Z$-scores indicate that the infants in our sample were much shorter and lighter, compared to the international standard. 
Table 1. Socio-demographic characteristics of the sample

\begin{tabular}{|c|c|c|}
\hline Characteristics & Frequency $(n)$ & $\%$ \\
\hline \multicolumn{3}{|l|}{ Age of children (months) } \\
\hline Under 12 months & 151 & $35 \cdot 8$ \\
\hline 12-23 months & 208 & $49 \cdot 3$ \\
\hline 24-36 months & 63 & 14.9 \\
\hline \multicolumn{3}{|l|}{ Maternal age (years) } \\
\hline Under 25 years & 59 & $14 \cdot 0$ \\
\hline $25-34$ years & 212 & $50 \cdot 2$ \\
\hline At least 35 years & 151 & $35 \cdot 8$ \\
\hline \multicolumn{3}{|l|}{ Educational level of mothers } \\
\hline None & 209 & $49 \cdot 5$ \\
\hline Low (Primary and Junior High School (JHS)) & 127 & $30 \cdot 1$ \\
\hline High (at least Senior High School (SHS)) & 86 & $20 \cdot 4$ \\
\hline \multicolumn{3}{|l|}{ Household wealth index } \\
\hline Low (<median of 8) & 181 & $42 \cdot 9$ \\
\hline High (at least 8) & 241 & $57 \cdot 1$ \\
\hline \multicolumn{3}{|l|}{ Religion } \\
\hline Christianity & 209 & $49 \cdot 5$ \\
\hline Islam & 185 & 43.8 \\
\hline ATR & 27 & $6 \cdot 4$ \\
\hline \multicolumn{3}{|l|}{ Occupation } \\
\hline Trader & 98 & 24.5 \\
\hline Farmer & 123 & $30 \cdot 8$ \\
\hline Service provider & 67 & $16 \cdot 8$ \\
\hline Salary worker (e.g. teacher and health worker) & 10 & $2 \cdot 4$ \\
\hline Nothing & 102 & $25 \cdot 5$ \\
\hline \multicolumn{3}{|l|}{ Ethnicity } \\
\hline Kusasi & 322 & $76 \cdot 3$ \\
\hline Mamprusi & 12 & $2 \cdot 8$ \\
\hline Moshi & 17 & $4 \cdot 0$ \\
\hline Others & 71 & $16 \cdot 9$ \\
\hline
\end{tabular}

Table 2. Nutritional status of mothers and children aged 0-36 months

\begin{tabular}{lrrr}
\hline Characteristics & Mean \pm SD & Frequency $(n)$ & $\%$ \\
\hline Nutritional status & & & \\
$\quad$ Height-for-age Z-score & $-0.92 \pm 2 \cdot 2$ & & \\
Weight-for-height Z-score & $0.28 \pm 1 \cdot 7$ & & \\
Weight-for-age Z-score & $-0.38 \pm 1.33$ & & \\
$\%$ Stunted (HAZ $<-2)$ & & 117 & 27.7 \\
$\%$ Wasted $(\mathrm{WHZ}<-2)$ & 33 & 7.8 \\
$\%$ Underweight $(\mathrm{WAZ}<-2)$ & 39 & 9.2 \\
Maternal short stature $<150 \mathrm{~cm}(\%)$ & 19 & 4.5 \\
Maternal BMl<18.5 kg/m ${ }^{2}$ & & 29 & 6.9 \\
\hline
\end{tabular}

Levels of maternal autonomy in the study population.

Table 3 shows the aspects of maternal decision-making autonomy, while Table 4 shows the level of freedom of movement. In this study, $82.9 \%$ of women were autonomous in what to do when the child fell sick facilities,

Table 3. Maternal involvement in household final say on key decisions

\begin{tabular}{lll}
\hline Decision & Frequency $(n)$ & $\%$ \\
\hline Your own health care? & 366 & $86 \cdot 7$ \\
Making large household purchases? & 292 & $69 \cdot 2$ \\
Making household purchases for daily needs? & 359 & $85 \cdot 1$ \\
Visits to family or relatives? & 298 & $70 \cdot 6$ \\
What food should be cooked each day? & 327 & $77 \cdot 5$ \\
You should do work to earn money? & 342 & $81 \cdot 0$ \\
What to do if a child falls sick? & 350 & $82 \cdot 9$ \\
Having another child? & 282 & $66 \cdot 8$ \\
\hline
\end{tabular}

Table 4. Are you usually allowed to go to the following places on your own?

\begin{tabular}{lll}
\hline Place & Frequency $(n)$ & $\%$ \\
\hline Freedom to see a doctor when sick & 178 & $42 \cdot 2$ \\
Just outside your house or compound? & 394 & 93.4 \\
Local market to buy things? & 418 & $99 \cdot 1$ \\
Local health centre or doctor? & 405 & $96 \cdot 0$ \\
In the neighbourhood for recreation? & 341 & $80 \cdot 8$ \\
Home of relatives or friends in the & 308 & 73.0 \\
$\quad$ neighbourhood? & & \\
\hline
\end{tabular}

while $85.1 \%$ of women were involved in making household purchases for daily needs. Decisions regarding all movements outside the house to some extent were restricted (i.e. warrants seeking permission from either husband or a senior household member).

The overall CIWA was categorised into low and high. Accordingly, $52 \cdot 8 \%$ of the respondents were of high autonomy and general maternal decision-making autonomy was the most restricted. The overall level of women's autonomy, as well as its components, is shown in Table 5.

Prevalence of child malnutrition among women with different levels of autonomy. The prevalence of stunting and wasting as stratified by maternal autonomy is shown in Table 6 . Health care autonomy, general maternal decision-making power and CIWA were negatively associated with stunting, but no discernible association existed between overall/components of maternal autonomy and wasting. Maternal freedom of movement (freedom of movement to homes of relatives) was associated negatively with stunting. Maternal financial independence was not associated with stunting.

Comparison of child growth and dietary indicators according to maternal health care autonomy. Table 7 shows unadjusted differences in mean child growth indices according to maternal health care autonomy using analysis of variance (ANOVA). The unadjusted values of mean length-for-age $Z$-score (LAZ) and child dietary diversity were

Table 5. Dimensions of women's autonomy

\begin{tabular}{lcc}
\hline Characteristics & Frequency $(n)$ & $\%$ \\
\hline $\begin{array}{l}\text { Composite index of women autonomy (CIWA) } \\
\text { Low } \\
\text { High }\end{array}$ & 199 & \\
Health care autonomy & 223 & 47.2 \\
Low & 211 & $52 \cdot 8$ \\
High & 211 & $50 \cdot 0$ \\
General maternal decision-making power & $50 \cdot 0$ \\
Low & 294 & \\
High & 128 & 69.7 \\
Maternal financial independence & $30 \cdot 3$ \\
Low & 251 & \\
High & 171 & 59.5 \\
Freedom of movement & 108 & 40.5 \\
Low & 314 & 25.6 \\
High & & 74.4 \\
\hline
\end{tabular}


Table 6. Prevalence of child malnutrition among women with different levels of maternal autonomy

\begin{tabular}{|c|c|c|c|c|}
\hline & $\begin{array}{c}\% \\
\text { Stunted }\end{array}$ & $\begin{array}{c}\text { Test } \\
\text { statistic }\end{array}$ & $\begin{array}{c}\% \\
\text { Wasted }\end{array}$ & $\begin{array}{l}\text { Test } \\
\text { statistic }\end{array}$ \\
\hline \multicolumn{5}{|c|}{ Composite index of women autonomy (CIWA) } \\
\hline $\begin{array}{l}\text { Low (<mean score } \\
\text { of } 10)\end{array}$ & $34 \cdot 2$ & $\begin{array}{l}\chi^{2}=7 \cdot 8 \\
P=0.005\end{array}$ & $7 \cdot 0$ & \multirow[t]{2}{*}{$\begin{aligned} \chi^{2} & =0.3 \\
P & =0.6\end{aligned}$} \\
\hline High (at least 10) & $22 \cdot 0$ & & 8.5 & \\
\hline \multicolumn{5}{|l|}{ Health care autonomy } \\
\hline $\begin{array}{l}\text { Low (< mean score } \\
\text { of } 3)\end{array}$ & $32 \cdot 2$ & $\begin{array}{l}\chi^{2}=4.3 \\
P=0.04\end{array}$ & $8 \cdot 1$ & \multirow[t]{2}{*}{$\begin{array}{c}\chi^{2}=0.03 \\
P=0.9\end{array}$} \\
\hline High (at least 3) & $23 \cdot 2$ & & $7 \cdot 6$ & \\
\hline \multicolumn{5}{|c|}{ General maternal decision-making power } \\
\hline $\begin{array}{l}\text { Low }(<\text { mean score } \\
\text { of } 5)\end{array}$ & $31 \cdot 6$ & $\begin{array}{l}\chi^{2}=7.39 \\
P=0.007\end{array}$ & $7 \cdot 1$ & \multirow[t]{2}{*}{$\begin{aligned} \chi^{2} & =0.6 \\
P & =0.4\end{aligned}$} \\
\hline High (at least 5) & $18 \cdot 8$ & & $9 \cdot 4$ & \\
\hline \multicolumn{5}{|c|}{ Maternal financial independence } \\
\hline $\begin{array}{l}\text { Low }(<\text { mean score } \\
\text { of } 3)\end{array}$ & 29.5 & $\begin{aligned} \chi^{2} & =0.9 \\
P & =0.3\end{aligned}$ & $7 \cdot 6$ & \multirow[t]{2}{*}{$\begin{aligned} \chi^{2} & =0.1 \\
P & =0.8\end{aligned}$} \\
\hline High (at least 3) & $25 \cdot 1$ & & $8 \cdot 2$ & \\
\hline \multicolumn{5}{|c|}{ Freedom of movement to homes of relatives } \\
\hline No & $35 \cdot 1$ & $\chi^{2}=4 \cdot 2$ & $10 \cdot 5$ & $\chi^{2}=1 \cdot 6$ \\
\hline Yes & $25 \cdot 0$ & $P=0.04$ & $6 \cdot 8$ & $P=0.2$ \\
\hline
\end{tabular}

positively associated with high women's autonomy, but weight-for-age (WAZ) and weight-for-length (WLZ) were not associated.

Using analysis of covariance (ANCOVA) that adjusted for age of the child, height of mother, gender of the child, WLZ, age of mother and religion of mother, there was a significant difference in mean LAZ between children of mothers who had high health care autonomy and children's whose mothers had low health care autonomy (-0.674 v. -1.159; $95 \%$ CI $0 \cdot 02,0 \cdot 65 ; P=0 \cdot 04)$.

Determinants of mean length-for-age Z-scores. A number of explanatory variables were tested for their association with LAZ. The variables tested included women's autonomy and its components, age and sex of child, current breast-feeding status, diarrhoeal infection, utilisation of antenatal care services, birth interval, parity, maternal height, maternal educational level, household wealth index, source of drinking water, type of toilet facility, bottle feeding, minimum dietary diversity score and number of under five children in household.

After adjusting (multiple regression analysis) for maternal and child characteristics confounders, women's autonomy was significantly and positively associated with length-for-age $Z$-score (LAZ). The mean LAZ of children born to women of high autonomy was significantly higher than LAZ of children born to women of low autonomy $(\beta=0 \cdot 132 ; P=$ 0.004; Table 8).

Female children were generally taller than male children by $0 \cdot 115$ standard units $(\beta=0.115 ; P=0 \cdot 01)$. A unit increase in the height of mother increases the mean LAZ increases by $0 \cdot 175$ standard units $(P<0 \cdot 001)$. Low WHZ (i.e. wasting) was the prominent determinant of LAZ as wasted children were taller by 0.304 standard units $(\beta=0.304 ; P<0.001)$. The mean LAZ of children born to mothers who follow African Traditional Religion (ATR) was significantly higher than LAZ of children born to Christian mothers. A unit increase in mother's body mass index (BMI) was associated with a $0 \cdot 118$ increase in LAZ $(P=0 \cdot 016)$. Children who were not bottle-fed were taller than bottle-fed children by $0 \cdot 111$ standard units $(\beta=0 \cdot 111 ; P=0 \cdot 01)$.

Similar determinants of postnatal child growth including women's autonomy were obtained when the outcome variable was treated as a categorical variable (i.e. stunted or not stunted). Logistic regression analysis showed that low autonomy, Christians, male child, low BMI of mother, bottle feeding, child not wasted, and height of mother were independently associated with an increased odd of stunted growth (Table 9). Compared to women of high autonomy, women of low autonomy were 1.9 times more likely of having stunted children (AOR =1.93; CI 1.21, 3.07).

Women who were Christians were 4.3 times more likely (AOR $=4 \cdot 25$; CI $1 \cdot 19,15 \cdot 17)$ of having stunted children, compared to women who were followers of ATR. Bottle-fed children who were 1.9 times (AOR $=1.88$; CI 1.09, 3.26) more likely to be stunted, compared to their counterparts

Table 7. Comparison of child growth and dietary indices according to maternal health care autonomy (Unadjusted differences)

\begin{tabular}{|c|c|c|c|c|c|c|c|}
\hline \multirow[b]{2}{*}{ Indicator } & \multirow[b]{2}{*}{ Women's autonomy } & \multirow[b]{2}{*}{$N$} & \multirow[b]{2}{*}{ Mean } & \multirow[b]{2}{*}{ SD } & \multicolumn{2}{|c|}{$\begin{array}{l}95 \% \text { confidence interval } \\
\text { for Mean }\end{array}$} & \multirow[b]{2}{*}{ Test statistics } \\
\hline & & & & & Lower bound & Upper bound & \\
\hline \multirow[t]{2}{*}{ HAZ } & Low & 211 & $-1 \cdot 16$ & $2 \cdot 17$ & -1.46 & -0.87 & $F(1,421)=5.65 ; P=0.02$ \\
\hline & High & 211 & -0.67 & $2 \cdot 12$ & -0.96 & -0.38 & \\
\hline \multirow[t]{2}{*}{ WHZ } & Low & 211 & 0.27 & 1.76 & 0.029 & 0.51 & $F(1,421)=0.02 ; P=0.9$ \\
\hline & High & 211 & 0.29 & $1 \cdot 70$ & 0.06 & 0.52 & \\
\hline \multirow[t]{2}{*}{ WAZ } & Low & 211 & -0.50 & $1 \cdot 23$ & -0.66 & -0.33 & $F(1,421)=3.49 ; P=0.06$ \\
\hline & High & 211 & -0.27 & $1 \cdot 24$ & -0.4394 & -0.10 & \\
\hline \multirow{2}{*}{ Child dietary diversity score (DDS) } & Low & 211 & 2.44 & $1 \cdot 78$ & $2 \cdot 20$ & $2 \cdot 68$ & $F(1,420)=6.54 ; P=0.01$ \\
\hline & High & 210 & $2 \cdot 89$ & $1 \cdot 83$ & $2 \cdot 64$ & $3 \cdot 14$ & \\
\hline \multirow[t]{2}{*}{ Maternal DDS } & Low & 211 & $4 \cdot 68$ & 1.53 & 4.47 & 4.89 & $F(1,421)=1.97 ; P=0.2$ \\
\hline & High & 211 & 4.48 & 1.38 & 4.29 & 4.67 & \\
\hline \multirow[t]{2}{*}{ BMI of mother } & Low & 211 & 23.35 & $6 \cdot 30$ & 22.49 & $24 \cdot 20$ & $F(1,421)=0.09 ; P=0.8$ \\
\hline & High & 211 & $23 \cdot 19$ & 3.43 & $22 \cdot 73$ & $23 \cdot 66$ & \\
\hline \multirow[t]{2}{*}{ Maternal weight } & Low & 211 & $62 \cdot 00$ & $10 \cdot 53$ & $60 \cdot 57$ & 63.43 & $F(1,421)=1.9 ; P=0.2$ \\
\hline & High & 210 & 65.62 & 36.03 & $60 \cdot 72$ & $70 \cdot 52$ & \\
\hline
\end{tabular}


Table 8. Determinants of mean length-for-age Z-scores (Multivariable regression analysis)

\begin{tabular}{|c|c|c|c|c|c|c|}
\hline \multirow[b]{2}{*}{ Model } & \multirow{2}{*}{$\begin{array}{l}\text { Standardized } \\
\text { coefficients } \\
\beta\end{array}$} & \multirow[b]{2}{*}{ Sig. } & \multicolumn{2}{|c|}{$95 \%$ confidence interval for $\beta$} & \multicolumn{2}{|c|}{ Collinearity statistics } \\
\hline & & & Lower bound & Upper bound & Tolerance & Variance inflation factor (VIF) \\
\hline (Constant) & & 0.000 & $-15 \cdot 32$ & -6.94 & & \\
\hline BMI of mother & 0.118 & 0.016 & 0.011 & 0.11 & 0.834 & 1.199 \\
\hline High women's autonomy & 0.132 & 0.004 & 0.19 & 0.95 & 0.988 & $1 \cdot 012$ \\
\hline Child wasting & 0.304 & $<0.001$ & 1.71 & $3 \cdot 12$ & 0.989 & $1 \cdot 012$ \\
\hline Height of mother & 0.175 & $<0.001$ & 0.02 & 0.06 & 0.820 & $1 \cdot 219$ \\
\hline African Traditional Religion (ATR) & 0.144 & 0.001 & 0.20 & 0.81 & 0.985 & 1.016 \\
\hline Female child & 0.115 & 0.011 & 0.115 & 0.88 & 0.991 & 1.010 \\
\hline No bottle feeding & 0.111 & 0.013 & 0.13 & 1.08 & 0.990 & 1.010 \\
\hline
\end{tabular}

Table 9. Determinants of child stunting (Binary logistic regression analysis)

\begin{tabular}{llllll}
\hline & & & & \multicolumn{3}{c}{$95 \% \mathrm{Cl}$ for } \\
& & & & \multicolumn{3}{c}{$\operatorname{Exp}(\beta)$} \\
\cline { 3 - 6 } & Wald & Sig. & $\operatorname{Exp}(\beta)$ & Lower & Upper \\
\hline Low autonomy & 7.606 & 0.006 & 1.927 & 1.209 & 3.071 \\
$\begin{array}{l}\text { Religion (Reference: } \\
\quad \text { African traditional }\end{array}$ & 6.631 & 0.04 & & & \\
$\quad$ religion (ATR)) & & & & & \\
Christianity & 4.983 & 0.03 & 4.25 & 1.19 & 15.17 \\
Islam & 2.561 & 0.110 & 2.863 & 0.79 & 10.38 \\
Male child & 5.696 & 0.02 & 1.78 & 1.11 & 2.86 \\
BMl of mother & 8.673 & 0.003 & 0.91 & 0.86 & 0.97 \\
$\begin{array}{l}\text { Bottle feeding } \\
\text { Not wasted }\end{array}$ & 5.123 & 0.024 & 1.88 & 1.09 & 3.26 \\
Height of mother & 6.318 & 0.012 & 4.88 & 1.42 & 16.80 \\
Constant & 14.065 & $<0.001$ & 0.95 & 0.92 & 0.98 \\
\hline
\end{tabular}

who were not bottle-fed. Male children were 1.8 times more likely $(\mathrm{AOR}=1 \cdot 78$; CI $1 \cdot 11,2 \cdot 86)$ to be stunted, compared to female children.

Children who were not wasted were 4.9 times more likely $(\mathrm{AOR}=4 \cdot 88$; $\mathrm{CI} 1.42,16 \cdot 80)$ to be stunted children, compared to children who were wasted.

A unit increase in maternal height was associated with $5 \%$ protection against child stunting (AOR $=0.95$; CI $0.92,0 \cdot 98$ ). Similarly, a unit increase in a mother's BMI was associated with $9 \%$ protection against child stunting $(\mathrm{AOR}=0.91$; CI $0 \cdot 86,0 \cdot 97)$.

The set of variables alone accounted for $17 \cdot 1 \%$ (Nagelkerke R Square $=0 \cdot 171$ ) of the variability in stunted growth in children. It is also an indication that other factors contribute to the dependent variable but were not measured in this study.

An additional interaction term between the autonomy variable and age grouping of child was included in the logistic regression model to assess whether the age of children interacts with the relationship between women's autonomy and stunting. The interaction term was very significant after adjusting for some potential covariates $(\mathrm{AOR}=0 \cdot 71$; CI 0.56, 0.90; $P=0 \cdot 004)$. The strongest association between women's autonomy and stunting was found among children aged 12-23 months, compared to other groups of children.

As a result of the interaction between women's autonomy and age of child, the protective effect of autonomy varied across age groups. Whereas high autonomy protected $60 \%$ of the probability of stunting among children aged 12-23 months, there was only an insignificant reduction in children aged 6-11 months. There was no discernible beneficial benefit of women's autonomy on stunting among children under 6 months and children aged 24-36 months (Table 10).

Relationship between women's autonomy and child feeding practices. After controlling for confounders, women with higher overall women's autonomy were more likely to feed their children with the minimum required dietary diversity (AOR $=1.69$; CI 1.12, 2.54) as compared with women with lower autonomy. Similarly, higher women's autonomy was associated with a higher likelihood of feeding an MAD $(\mathrm{AOR}=1.59$; $\mathrm{CI} 1.09,2 \cdot 34)$. The only component that associated positively with MAD in this study population was maternal financial independence (Table 11). Overall women's autonomy, maternal financial independence and freedom of movement to homes of relatives were also associated with a composite feeding index which measured complete feeding practices for infants and young children.

As presented in Table 12, there was a strong positive association between overall women's decision-making autonomy and key child feeding indicators including timely initiation of breast feeding $(P<0 \cdot 001)$, feeeding of diversified diets $(P=$ $0 \cdot 001), \operatorname{MAD}(P=0 \cdot 004)$ and the overall composite ICFI $\left(\chi^{2}=5 \cdot 9 ; P=0 \cdot 02\right)$. However, no association was observed between women's autonomy and timely introduction of complementary foods.

Table 10. Crude odds ratio (COR) of women's autonomy for stunting according to age of child

\begin{tabular}{lccccc}
\hline & \multicolumn{5}{c}{ Age groups of children (months) } \\
\cline { 2 - 6 } & Under 6 & $6-11$ & $12-23$ & $24-36$ & All ages \\
\hline $\begin{array}{l}\text { Child-level equation } \\
\quad \text { Intercept for stunting }\end{array}$ & -0.575 & -0.804 & -0.568 & -0.754 & -0.656 \\
$\quad$ constant) & & & & & \\
Standard error (SE) & 0.550 & 0.530 & 0.323 & 0.599 & 0.220 \\
Wald & 0.862 & 3.077 & 8.105 & 1.502 & 7.712 \\
Odds ratio (Exp( $\beta)$ ) & 1.67 & 0.39 & 0.40 & 0.48 & 0.54 \\
95\% confidence & 0.57, & 0.14, & 0.21, & 0.15, & 0.35 \\
$\quad$ interval for Exp ( $\beta)$ & 4.90 & 1.12 & 0.75 & 1.55 & 0.84 \\
$P$ value & 0.4 & 0.08 & 0.004 & 0.22 & 0.005 \\
\hline
\end{tabular}


Table 11. Association between women's autonomy dimensions and IYCF practices among children aged 6-23 months

\begin{tabular}{|c|c|c|c|}
\hline \multirow[b]{2}{*}{ Autonomy/Dimension } & \multicolumn{3}{|c|}{ AOR $(95 \% \mathrm{Cl})$ of IYCF practices ${ }^{\mathrm{b}}$} \\
\hline & Minimum dietary diversity & Minimum acceptable diet & Classification of ICFI \\
\hline Composite index of women autonomy (CIWA) & $1.69(1.12,2.54) a$ & $1.59(1.09,2.34) a$ & $1.52(1.04,2.22) a$ \\
\hline Health care autonomy & $1.38(0 \cdot 89,2 \cdot 12)$ & $1.52(0.97,2.36)$ & $1.06(0.66,1.70)$ \\
\hline General maternal decision-making power & $1.34(0.90,1.99)$ & $1.18(0.81,1.71)$ & $1.31(0.90,1.91)$ \\
\hline Maternal financial independence & $1.52(0.99,2.32)$ & $1.84(1.23,2 \cdot 75) a$ & $1.68(1.11,2.54) a$ \\
\hline Freedom of movement to homes of relatives & $1.46(0.89,2.40)$ & $1.14(0.68,1.89)$ & $1.90(1.13,3.20) a$ \\
\hline
\end{tabular}

a Significant.

b Confounders adjusted for include breast-feeding status, child age, mothers' occupation type, timely introduction of complementary food at 6 months.

Table 12. Association between child feeding practices and overall women's autonomy (Bivariable analysis)

\begin{tabular}{|c|c|c|c|}
\hline \multirow[b]{2}{*}{ Characteristic } & \multicolumn{2}{|c|}{$\begin{array}{l}\text { Classification of overall } \\
\text { women's autonomy }\end{array}$} & \multirow[b]{2}{*}{ Test statistic } \\
\hline & Low $n(\%)$ & High $n(\%)$ & \\
\hline \multicolumn{4}{|c|}{ Timely initiation of breast feeding } \\
\hline No & $83(40.5)$ & $82(25.9)$ & \multirow[t]{2}{*}{$\chi^{2}=12.4 ; P<0.001$} \\
\hline Yes & $122(59 \cdot 5)$ & $235(74 \cdot 1)$ & \\
\hline \multicolumn{4}{|c|}{ Minimum dietary diversity - children } \\
\hline Less than 4 & $102(49 \cdot 8)$ & $111(35 \cdot 0)$ & \multirow[t]{2}{*}{$\chi^{2}=11.1 ; P=0.001$} \\
\hline At least 4 & $103(50 \cdot 2)$ & $206(65.0)$ & \\
\hline \multicolumn{4}{|c|}{ Timely introduction of complementary foods } \\
\hline No & $122(59.5)$ & $183(57 \cdot 7)$ & \multirow[t]{2}{*}{$\chi^{2}=0.2 ; P=0.7$} \\
\hline Yes & $83(40.5)$ & $134(42 \cdot 3)$ & \\
\hline \multicolumn{4}{|c|}{ Minimum acceptable diet } \\
\hline No & $116(56 \cdot 6)$ & $139(43 \cdot 8)$ & \multirow[t]{2}{*}{$\chi^{2}=8 \cdot 1 ; P=0.004$} \\
\hline Yes & $89(43.4)$ & $178(56 \cdot 2)$ & \\
\hline \multicolumn{4}{|c|}{ Appropriate complementary feeding rate } \\
\hline No & $166(81 \cdot 0)$ & $226(71 \cdot 3)$ & \multirow[t]{2}{*}{$\chi^{2}=6.2 ; P=0.01$} \\
\hline Yes & $39(19 \cdot 0)$ & $91(28 \cdot 7)$ & \\
\hline \multicolumn{4}{|c|}{ Classification of Infant and child feeding index (ICFI) } \\
\hline Low & $77(37.6)$ & $87(27.4)$ & \multirow{2}{*}{$\chi^{2}=5.9 ; P=0.02$} \\
\hline High & $128(62.4)$ & $230(72 \cdot 6)$ & \\
\hline
\end{tabular}

Determinants of meeting MAD (Binary logistic regression analysis). After controlling for potential confounding factors in logistic regression analysis, high women's autonomy remains a significant independent predictor of meeting $\mathrm{MAD} \quad(\mathrm{AOR}=1 \cdot 59 ; \quad \mathrm{CI} 1 \cdot 09,2 \cdot 34)$. Other determinants included were age of the child, children whose mothers were farmers, timely introduction of complementary foods at 6 months and non-breast-feeding children. Older children (12-23 months) were associated with 4.38 odds of meeting MAD (AOR $=4 \cdot 38$; CI 2.86, 6.69). Children who were timely introduced to complementary foods at 6 months were 2.0 times more likely of meeting $\mathrm{MAD}(\mathrm{AOR}=2.08$; CI 1.42, 3.07), compared with their colleagues who were fed with such foods on any other time. Children whose mothers reported they were farmers were 1.7 times more likely of meeting MAD (AOR $=1.69$; CI 1.08, 2.65), compared to children whose mothers were non-farmers (Table 13). The set variables alone accounted for $20.5 \%$ (Nagelkerke R Square $=0 \cdot 205)$ of the variability in MAD.

\section{Discussion}

This present study sought to assess the relationship between women's autonomy, child feeding practices and growth
Table 13. Determinants of meeting minimum acceptable diet (Binary logistic regression analysis)

\begin{tabular}{|c|c|c|c|c|c|}
\hline & \multirow[b]{2}{*}{ Wald } & \multirow[b]{2}{*}{ Sig. } & \multirow{2}{*}{$\begin{array}{l}\operatorname{Exp} \\
(\beta)\end{array}$} & \multicolumn{2}{|c|}{$\begin{array}{l}95 \% \mathrm{Cl} \text { for } \\
\operatorname{Exp}(\beta)\end{array}$} \\
\hline & & & & Lower & Upper \\
\hline High women autonomy & $5 \cdot 635$ & 0.018 & 1.59 & 1.09 & $2 \cdot 34$ \\
\hline Occupation (Farmer) & $5 \cdot 251$ & 0.022 & 1.69 & 1.08 & $2 \cdot 65$ \\
\hline $\begin{array}{l}\text { Child's age (Reference: } \\
6-11 \text { months) }\end{array}$ & $46 \cdot 459$ & $<0.001$ & & & \\
\hline 12-23 months & 46.459 & $<0.001$ & 4.38 & $2 \cdot 86$ & 6.69 \\
\hline 24-35 months & $5 \cdot 437$ & 0.020 & $2 \cdot 361$ & $1 \cdot 147$ & $4 \cdot 861$ \\
\hline $\begin{array}{l}\text { Timely introduction of } \\
\text { complementary foods }\end{array}$ & $13 \cdot 940$ & $<0.001$ & $2 \cdot 084$ & 1.417 & 3.065 \\
\hline $\begin{array}{l}\text { Not currently breast } \\
\text { feeding }\end{array}$ & 3.788 & 0.052 & $2 \cdot 055$ & 0.995 & $4 \cdot 244$ \\
\hline Constant & 41.836 & 0.000 & 0.156 & & \\
\hline
\end{tabular}

indicators in a setting where malnutrition is high and decisionmaking at the household and community levels is largely dominated by men. The main finding was that overall maternal autonomy, positively associated with child feeding practices and protected against child stunting after controlling for key confounders such as gender of child, bottle feeding and height of mother.

The study findings further suggest that not all dimensions of women's autonomy were positively associated with child growth. The basic assumption in the study was that access to and control of resources is an essential ingredient for adequate health care and for that matter autonomous women may cater very well for their own health and that of their children. The health care autonomy decision-making was the best predictor of child growth, but maternal financial independence dimension associated more with child feeding practices. Women's autonomy which is a multidimensional, intangible and latent concept is expressed in several ways, such as decision-making power and control of household resources and the extent of freedom of movement ${ }^{(26-28)}$.

\section{Women's autonomy level in the study population}

In our study sample, though presumed to be male-dominated, the majority of women had high autonomy with regards to decision-making on important matters that affect them. This finding collaborates that of Sethuraman et al. ${ }^{(29)}$, who reported that the majority of mothers make an important decision in 
their various household. Decisions regarding movements outside the house to some extent were generally free though some were restricted (i.e. warrants seeking permission from either husband or a senior household member). Similarly, other studies found out that the majority of the mothers could go to the health centres on their own without seeking permission from their husbands or a senior household member ${ }^{(30)}$.

Association between dimensions of women's autonomy and child growth indicators

Though available evidence suggests a positive relationship between maternal autonomy and better child nutritional status ${ }^{(4,31)}$, little is known about how the various dimensions of women's autonomy influence postnatal child growth. The present study investigated the association between stunted growth and overall women's autonomy and its dimensions.

Health care autonomy, general maternal decision-making power and CIWA were negatively associated with stunting, but no discernible association existed between overall/dimensions of maternal autonomy and wasting. Maternal freedom of movement, particularly, freedom of movement to homes of relatives was associated negatively with stunting. This finding supports that of Shroff et al. ${ }^{(5)}$ who found out that not needing permission to go the market decrease the likelihood that a child will be stunted. However, maternal financial independence was not associated with stunting in our sample.

Similar findings have been reported that, when mothers have autonomy over child feeding and childcare, they may be more likely to follow recommended feeding practice and can reduce the likelihood of stunting among children ${ }^{(32,33)}$.

Similarly, after controlling for maternal and child characteristics confounders, the adjusted values of mean length-for-age $Z$-score (LAZ) were significantly and positively associated with health care autonomy decision-making power, but weight-for-age (WAZ) and weight-for-length (WLZ) were not.

As reported in other studies, the results of our study indicated that neither the overall women's autonomy nor its components had a significant effect on children's nutrition as measured by WLZ scores ${ }^{(3,33)}$ though others have reported of a positive association between mother's autonomy score and $\mathrm{WLZ}^{(3)}$. For example, in a Kenyan study, greater levels of women's autonomy were significantly associated with improved scores of WLZ scores among older children aged 3-10 years but not with children younger.

WLZ provides a recent measure of children's health compared to LAZ, and therefore, one would have expected that women's autonomy which, reflects the current ability of women to control household resources will negatively associate with child wasting. It is, however, important to note that prolong wasting can lead to stunting ${ }^{(34,35)}$, which is an outcome of chronic deprivation. Furthermore, though women's autonomy was measured as the current ability of women to make independent decisions regarding among others control of household resources, it is possible that this multidimensional characteristic of autonomy could remain stable through time and can impact on stunting.
The results of the present study show that the overall maternal autonomy had a significant positive impact on LAZ and a negative impact upon stunting. This finding confirms that of earlier studies carried out in many geographical locations ${ }^{(33)}$.

In other places, including rural Nepal, India and Haiti, higher health care decision-making power and mobility autonomy are reported to be significant predictors of improved height-for-age $Z$-scores after controlling for potential covariates $(3,11,30,33,36,37)$. This relationship may be partly explained by the fact that mothers with greater autonomy may benefit in other ways that indirectly affect their child. For example, they are more likely to make greater use of available health services such as antenatal care. Past studies have reported that women with greater autonomy are more likely to seek health care for themselves and use different forms of health care services available to them ${ }^{(26,38,39)}$. However, some other studies conducted elsewhere including Kenya and Nepal showed that maternal autonomy has a limited or no influence on child nutrition measures ${ }^{(13-16)}$. The discrepancies may be attributed to differences in outcome measures, ages of target children and the measurement of autonomy. For example, in the Kenyan study, the impact of women's autonomy on children's health was focused on short-term measurements of children's nutrition and growth, such as WHZ scores. Another possible reason for the conflicting results in these studies is how autonomy has been defined and measured by different researchers. In our study, we had to distinguish between general household decision-making from health-related decision-making autonomy. In the measurement of autonomy, the Kenyan study lumped general and health-related decision-making questions together and some of these may not be sensitive to child growth determinants. There is also the issue of some studies combining different components into a composite index and treating that as overall autonomy.

A possible interaction between age of child and women's autonomy on stunting was also investigated and found to be significant. The protective effect of autonomy against stunting varied according to age group of the child and the highest protection of $60 \%$ was found among children aged 12-23 months. There was, however, no discernible beneficial benefit of women's autonomy on stunting among children under 6 months and children aged 24-36 months (Table 10). The children under 6 months of age will mostly be on breastmilk and may, therefore, not be sensitive to the benefits of women's autonomy.

Available evidence strongly suggests that the first 2 years of life are considered to be the most important 'window of opportunity' to make a long-term impact upon children's nutritional status ${ }^{(40)}$. Therefore, the finding that more autonomous mothers are able to protect against stunted growth especially during a specific period of the window is very crucial for policy and programming purposes.

Mechanism of the relationship between women's autonomy and child nutrition

Based on the findings of the present study and others, an important question that has not been fully answered is the 
how and why greater autonomy leads to better child nutrition outcomes: What kind of decisions do women of greater autonomy make that improve the nutritional outcomes of their children?

Emerging evidence suggests that the positive link between women's autonomy and child nutrition may be explained by care behaviours shown by mothers. It has been shown that care behaviours are crucial for children's optimal growth, development and survival ${ }^{(41)}$. Availability of resources to caregivers is crucial in determining positive care behaviours. Among others, women's autonomy determines how well positive care behaviours will be exhibited. Autonomy indicates the ability of caregivers to have a control of their surroundings ${ }^{(4,41)}$. In many societies around the world, mothers are primary caregivers, and resources available to them may play a pivotal role in determining care behaviours ${ }^{(41,42)}$. Care behaviours comprise infant and young child feeding (IYCF), hygiene, health-seeking, and family care and maternal resources for that. In this study, health care decision-making autonomy which reflected the involvement of mothers in household decisions about their own health care, seeing a doctor and care of children during sickness was the most influential dimension on child growth. Health care autonomy perhaps allows mothers to make decisions in favour of children, and more likely to spend on health and nutrition ${ }^{(43,44)}$. The pathway that links low women's autonomy and child malnutrition is either through maternal own nutritional status which may affect the effective use of maternal resources or through reduced access to and control of household resources for childcare $^{(45)}$

There were other covariates for both the HAZ and stunted growth as presented in Tables 8 and 9. This included religion, gender of child, height and BMI of mother, bottle feeding practices and whether or not the child was wasted or not.

Relative to female children, male children had a higher probability of becoming stunted, a finding that has been reported by earlier studies ${ }^{(46-48)}$. The exact factors contributing to this male vulnerability is unclear but it is unlikely to be the result of gender preference ${ }^{(46,49)}$. The male vulnerability to undernutrition may be biological and the fact that male children are at greater risk of infection because of a greater tendency to explore the environment compared to female counterparts. It has been suggested that despite the improvement in medical care, environmental stresses have harsher effects on males than females in early life ${ }^{(50)}$.

Compared to children of ATR, Christians and Muslim children had a higher probability of being stunted. This is consistent with findings of other studies ${ }^{(33)}$.

Bottle-fed children had greater odds of becoming stunted, compared to their counterparts who were not bottle-fed. This may be because of increased infection associated with feeding bottles among women who for one reason or the other are unable to thoroughly clean these bottles. Interestingly, most of the other WHO recommended complementary feeding indicators (minimum meal frequency, minimum dietary diversity and MAD) were not associated with child growth indicators among children aged 6-23 months. The apparent lack of association may be due to the fact that there was very little variation in the study population with respect to these indicators. The lack of association may also be explained partly by the fact that the feeding indicators may not be sensitive to chronic undernutrition because they are assessed based on 24-hour recall which may not give the usual dietary intake.

Surprisingly, children who were not wasted had a greater likelihood of becoming stunted compared to children who were wasted. However, some studies including a recent one in the Gambia reported that being wasted was predictive of stunting ${ }^{(51,52)}$. The present study was cross-sectional and so though wasting could lead to stunting, that does not mean that all wasted children are stunted and non-wasted can equally be stunted at any given point in time. The finding also suggests that linear growth may take place in the presence of wasting, such that wasted children may not necessarily be stunted after all.

The results also show that a unit increase in maternal height was associated with $5 \%$ protection against child stunting, and similarly, a unit increase in a mother's BMI was associated with $9 \%$ protection against child stunting. This confirms earlier research findings that high maternal height ${ }^{(53,54)}$ is positively associated with improved child nutrition. The significant association between stunting and maternal characteristics indicates that nutrition interventions must equally focus on children and their mothers. It is indeed advocated that empowering women by improving their health is one of the best approaches to promoting the health and well-being of children in developing countries $^{(55)}$.

The set of variables measured could accounted for $17 \cdot 1 \%$ of the variability in stunted growth in children. This is an indication that other factors contribute to the dependent variable but were not measured in this study.

\section{Association between women's autonomy and child feeding practices}

There is a dearth of knowledge on the relationship between women's autonomy and IYCF, particularly with regards to which of dimensions of women's autonomy is relevant in addressing poor infant and child feeding practices. The present study investigated the association between WHO recommended IYCF practices and overall women's autonomy and its dimensions and the key finding was that overall maternal autonomy was associated with child feeding practices after controlling for key confounders such as age of child, bottle and breast-feeding status of child. IYCF practices are a major component of child caring practices.

The finding is consistent with previous studies ${ }^{(17,36,56,57)}$, which reported that maternal autonomy positively associated with child feeding practices especially improved dietary diversity in Vietnam, Ghana, South Asia and Sub-Saharan Africa. Similarly, several other studies have reported positive associations between women's empowerment and dietary diversity of the child ${ }^{(58-60)}$. When mothers have decision-making autonomy over child feeding and childcare, they may be more likely to follow recommended feeding practices or provide more appropriate care ${ }^{(32)}$. 
An assessment of which dimensions of women's autonomy are associated with appropriate infant and child feeding practices was also made. The only component that associated positively with MAD in this study population was maternal financial independence. Similar results were obtained in a study involving ten African countries where higher women's economic empowerment was associated with a higher likelihood of feeding an $\mathrm{MAD}^{(61)}$.

The positive association between higher women's financial independence and appropriate child feeding practices is expected because access to diversified diets increases with economic empowerment. Indeed, the financial constraint has been reported to be one of the major reasons mothers are unable to feed children more meals with nutritious foods in many countries, including India, Ethiopia and Uganda mothers ${ }^{(5,62,63)}$. It has been reported also that higher power over the financial resources may translate to a higher likelihood of better resources allocated for child nutrition ${ }^{(64)}$.

In an analysis conducted using data from ten Demographic and Health Surveys, women's empowerment which involves the ability to influence decision-making in many life aspects found varied results in the countries. Whereas women's empowerment consistently and positively associated with multiple IYCF practices in Mali, Rwanda and Sierra Leone, there were null or mixed results in the remaining countries ${ }^{(61)}$. The study further concluded that women's empowerment for IYCF practices needs to be seen in terms of context and dimension of empowerment.

It has been reported that only one in three or one in six 623-month-old children in Sub-Saharan Africa were fed adequately diverse or overall acceptable diets, respectively ${ }^{(65)}$. Since women's autonomy has been shown to positively impact on feeding practices, it stands to reason that it should be aggressively be promoted towards optimal child care behaviours and better nutritional outcomes.

\section{Strengths and limitations of this study}

The present study adds to the past work on the relationship between women's autonomy and child growth in a number of ways. First, it has collaborated past research showing a positive link between women's autonomy and child nutrition and also adds that the protective effect of autonomy is dependent on child's age. Though autonomy is a multidimensional construct, the majority of past research focuses on one of two dimensions of autonomy such as decision-making autonomy. This study differs in that several dimensions of maternal autonomy were measured concurrently as a multidimensional concept. The results have shown that different dimensions do have differing impacts on child nutrition and this is relevant to public health interventions because the most important aspects of women's autonomy were made clearer.

Furthermore, the study tested the relationship between women's autonomy and anthropometric measures of child growth and found that it associated with only length-for-age $Z$-score (LAZ) but not weight-for-age (WAZ) and weight-for-length (WLZ).
However, there are some limitations to the study which need to be considered. The analytical cross-sectional study design limits the ability to draw any causal conclusions since the problem of bias cannot be ruled out. Furthermore, one round of 24-hour dietary recall was used to calculate dietary intake. The method is retrospective and therefore depends on memory and the ability of respondents to recall accurately. Recall bias could not be ruled out completely. The 24-hour dietary recall may not truly represent the usual intake. However, a single 24 hour provides an estimate of mean intake of foods and nutrients ${ }^{(66)}$.

Another limitation of this study was that only women were interviewed. Ghuman et al. ${ }^{(67)}$ suggested that measurements of women's autonomy change depending on whom - a woman or her husband - was interviewed. Nonetheless, our results have thrown more light on the association between maternal autonomy and nutritional status of children less than 2 years in the Bawku West District of Ghana.

\section{Conclusions and recommendations}

The findings of the study suggest that high women's autonomy was strongly and positively associated with mean height-for-age $Z$-score (HAZ and MAD). Therefore, policies and nutrition interventions focusing on women's autonomy may enhance women's ability to make health care decisions for themselves and their children, thereby speeding progress towards accomplishing many of the SDGs targeted at women and children.

\section{Acknowledgements}

I wish to acknowledge the co-operation of the study mothers and the community health volunteers during the data collection. Sincere thanks also go to members of the Bawku West District Health Directorate for their support.

There were no conflicts of interest.

This sole authorship by M.S. who contributed to all aspects of the research including the study design, data collection, statistical analyses interpretation of results and manuscript write-up.

\section{References}

1. UNICEF (1998) The Progress of Nations. New York: UNICEF.

2. Ross-Suits HM (2010) Maternal autonomy as a protective factor in child nutritional outcome in Tanzania,Thesis; Georgia State University.

3. Brunson EK, Shell-Duncan B \& Steele M (2009) Women's autonomy and its relationship to children's nutrition among the Rendille of northern Kenya. Am J Hum Bioliol 21, 55-64.

4. Carlson GJ, Kordas K \& Murray-Kolb LE (2015) Associations between women's autonomy and child nutritional status: a review of the literature. Matern Child Nutr 11, 452-482.

5. Shroff M, Griffiths P, Adair L, et al. (2009) Maternal autonomy is inversely related to child stunting in Andhra Pradesh, India. Matern Child Nutr 5, 64-74.

6. Mosca L, Benjamin EJ, Berra K, et al. (2011) Effectiveness-based guidelines for the prevention of cardiovascular disease in women -2011 update: a guideline from the American Heart Association. J Am Coll Cardiol 57, 1404-1423. 
7. Baatiema L, Skovdal M, Rifkin S, et al. (2013) Assessing participation in a community-based health planning and services programme in Ghana. BMC Health Serv Res 13. Article number: 233.

8. Hindin MJ (2000) Women's power and anthropometric status in Zimbabwe. Social Sci Med 51, 1517-1528.

9. Baqui AH, Arifeen SE, Amin S, et al. (1994) Levels and correlates of maternal nutritional status in urban Bangladesh. Eur J Clin Nutr $48,349-357$.

10. Rahman MM, Saima U \& Goni MA (2015) Impact of maternal household decision-making autonomy on child nutritional status in Bangladesh. Asia-Pac J Public Health 27, 509-520.

11. Ross-Suits H (2010) Maternal autonomy as a protective factor in child nutritional outcome in Tanzania. Public Health Theses, Georgia State University, Georgia, USA. Available at: http://scholarworks.gsu. edu/iph_theses/index.2.html (accessed 19 March 2020).

12. Shafiq A, Hussain A, Asif M, et al. (2019) The effect of "Women's Empowerment" on child nutritional status in Pakistan. Int I Environ Res Public Health 16, 4499.

13. Brunson EK, Shell-Duncan B \& Steele M (2009) Women's autonomy and its relationship to children's nutrition among the Rendille of northern Kenya. Am J Hum Biol 21, 55-64.

14. Dancer D \& Rammohan A (2009) Maternal autonomy and child nutrition: evidence from rural Nepal. Indian Growth Develop Rev 2 , $18-38$.

15. Rajaram R, Perkins JM, Joe W, et al. (2016) Individual and community levels of maternal autonomy and child undernutrition in India. Int I Public Health 8, 1-9.

16. Roushdy R (2004) Intra Housebold Resource Allocation in Egypt: Does Women's Empowerment Lead to Greater Investments in Children? Working Paper 0410 11, 306. Available at: http://paa2011.princeton.edu/papers/110550 (accessed 19 March 2020). Population Council, West Africa and North Asia Region.

17. Smith L, Ramakrishnan U, Ndiaye A, et al.. (2003) The Importance Of Women's Status for Child Nutrition in Developing Countries. IFPRI Reports 131. Washington, DC: IFPRI.

18. World Health Organization (2006) Child Growth Standards: Length/ Height-for-Age, Weight-for-Age, Weight-for-Length, Weight-for Height and Body Mass Index-Forage: Methods and Development. Geneva: WHO.

19. Hakim A, Sultan M \& ud din Ahmad F (2001) Pakistan Reproductive Health and Family Planning Survey. Preliminary Report Islamabad. Pakistan: National Institute of Population Studies.

20. WHO (2008) Indicators for Assessing Infant and Young Cbild Feeding Practices. Part 2: Measurements. Geneva: World Health Organization.

21. Vyas S \& Kumaranayake L (2006) Constructing socio-economic status indices: how to use principal components analysis. Health Policy Plan 21, 459-468.

22. Filmer D \& Pritchett LH (2001) Estimating wealth effects without expenditure data-or tears: an application to educational enrollments in states of India. Demography 38, 115-132.

23. Rutstein SO \& Johnson K (2004) DHS Comparative Reports 6: The DHS Wealth Index. Calverton, Maryland, USA: ORC Macro, MEASURE DHS.

24. Howe LD, Hargreaves JR \& Huttly SRA (2008) Issues in the construction of wealth indices for the measurement of socio-economic position in low-income countries. Emerg Themes Epidemiol 5, 3.

25. Dormann CF, Elith J, Bacher S, et al. (2013) Collinearity: a review of methods to deal with it and a simulation study evaluating their performance. Ecograpby 36, 27-46.

26. Bloom SS, Wypij D \& Gupta MD (2001) Dimensions of women's autonomy and the influence on maternal health care utilization in a North Indian City. Demography 38, 67-78.

27. Woldemicael G (2007) Do Women with Higher Autonomy Seek More Maternal and Child Health-Care? Evidence from Ethiopia and Eritrea. MPIDR Working Paper. Rostock, Germany: MPIDR.

28. Malhotra A \& Schuler SR (2005) Women's empowerment as a variable in international development:cross-disciplinary perspective. Washington DC: World Bank, 71-88.

29. Sethuraman K, Lansdown R \& Sullivan K (2006) Women's empowerment and domestic violence: the role of sociocultural determinants in maternal and child undernutrition in tribal and rural communities in South India. Food Nutr Bull 27, 128-143.

30. Shroff MR, Griffiths PL, Suchindran C, et al. (2011) Does maternal autonomy influence feeding practices and infant growth in rural India? Social Sci Med 73, 447-455.

31. Cunningham K, Ruel M, Ferguson E, et al. (2015) Women's empowerment and child nutritional status in South Asia: a synthesis of the literature. Matern Child Nutr 11, 1-19.

32. Shroff MR (2007) Child Nutritional Status, Feeding Practices and Women's Autonomy in Rural Andhra Pradesh, India. North Carolina at Chapel Hill: The University of North Carolina at Chapel Hill.

33. Arulampalam W, Bhaskar A \& Srivastava N (2016) Does Greater Autonomy among Women Provide the Key to Better Child Nutrition? Discussion Paper No 9781. Bonn, Germany: The Institute for the Study of Labor (IZA).

34. Walker SP \& Golden MH (1988) Growth in length of children recovering from severe malnutrition. Eur I Clin Nutr 42, 395-404.

35. Doherty CP, Sarkar MA, Shakur MS, et al. (2001) Linear and knemometric growth in the early phase of rehabilitation from severe malnutrition. Br J Nutr 85, 755-759.

36. Begin F, Frongillo Jr EA \& Delisle H (1999) Caregiver behaviors and resources influence child height-for-age in rural Chad. J Nutr 129, 680-686.

37. Desai S \& Johnson K (2005) Women's decision making and child health: familial and social hierarchies. A focus on gender. Collected papers on gender using DHS data. Women's Decisionmaking Child Health, 55-68.

38. Rahman MM, Mostofa MG \& Hoque MA (2014) Women's household decision-making autonomy and contraceptive behavior among Bangladeshi women. Sex Reprod Healthc 5, 9-15.

39. Upadhyay UD \& Hindin MJ (2005) Do higher status and more autonomous women have longer birth intervals?: Results from Cebu, Philippines. Soc Sci Med 60, 2641-2655.

40. UNICEF (2013) The Right Ingredients: The Need to Invest in Child Nutrition. Child Nutrition Report 2013. Available at: http://www. unicef.org.uk/Documents/Publicationpdfs/UNICEFUK_ChildNutrition Report2013w.pdf.

41. Engle PL, Menon P \& Haddad L (1999) Care and nutrition: concepts and measurement. World Dev 27, 1309-1337.

42. Coller RC \& Kuo AA. (2015) Children, families, and communities. In Child Health: A Population Perspective, pp. 49-77 [AA Kuo, RJ Coller, S Stewart-Brown \& M Blair Eds., ]. New York, NY: Oxford University Press.

43. Quisumbing AR \& Maluccio JA (2000) Intrabousebold Allocation and Gender Relations: New Empirical Evidence from Four Developing Countries. Washington, DC: International Food Policy Research Institute.

44. Thomas D (1990) Intra-household resource allocation: an inferential approach. J. Hum Resour 25, 635-664.

45. Segura SA, Ansótegui JA \& Díaz-Gómez NM (2016) The importance of maternal nutrition during breastfeeding: do breastfeeding mothers need nutritional supplements? Anales de Pediatría 84, 347-e1.

46. Medhin G, Hanlon C, Dewey M, et al. (2010) Prevalence and predictors of undernutrition among infants aged six and twelve months in Butajira, Ethiopia: the P-MaMiE Birth Cohort. BMC Public Health 10, 27.

47. Getahun Z, Urga K, Ganebo T, et al. (2001) Review of the status of malnutrition and trends in Ethiopia. Ethiop J Health Dev 15, 55-74.

48. Wamani H, Åstrøm AN, Peterson S, et al. (2007) Boys are more stunted than girls in Sub-Saharan Africa: a meta-analysis of 16 demographic and health surveys. BMC Pediatr 7, 17-26.

49. Hadley C, Lindstrom D, Tessema F, et al. (2008) Gender bias in the food insecurity experience of Ethiopian adolescents. Soc Sci Med 66, 427-438.

50. Wells JC (2000) Natural selection and sex differences in morbidity and mortality in early life. $J$ Theor Biol 202, 65-76.

51. Schoenbuchner SM, Dolan C, Mwangome M, et al. (2019) The relationship between wasting and stunting: a retrospective cohort analysis of longitudinal data in Gambian children from 1976 to 2016. Am J Clin Nutr 110, 498-507. 
52. Richard SA, Black RE, Gilman RH, et al. (2012) Wasting is associated with stunting in early childhood. J Nutr 142, 12911296.

53. Rahman M (2015) Is unwanted birth associated with child malnutrition in Bangladesh? Int Perspect Sex Reprod Health 41, 80-88.

54. Özaltin E, Hill K \& Subramanian SV (2010) Association of maternal stature with offspring mortality, underweight, and stunting in low- to middle-income countries. J Am Med Assoc 303, 15071516.

55. Leslie J, Lycette M \& Buvinic M (1988) Weathering economic crises: the crucial role of women in health. In Health, Nutrition and Economic Crises: Approaches to Policy in the Third World [DE Bell \& MR Reich Eds., ]. Dover, MA: Auburn House Publishing Company.

56. Bose S (2011) The effect of women's status and community on the gender differential in children's nutrition in India. J Biosocial Sci 43, 513-533.

57. Amugsi DA, Lartey A, Kimani-Murage E, et al. (2016) Women's participation in household decision-making and higher dietary diversity: findings from nationally representative data from Ghana. J Health Popul Nutr 35, e16.

58. Bhagowalia P, Menon P, Quisumbing AR, et al.2010et al. Unpacking the links between women's empowerment and cbild nutrition: evidence using nationally representative data from Bangladesh. Denver: Agricultural \& Applied Economics Association.

59. Bhagowalia P, Menon P, Quisumbing AR, et al. (2012) What Dimensions of Women's Empowerment Matter Most for Child Nutrition? Evidence Using Nationally Representative Data from Bangladesh. Washington: International Food Policy Research Institute.
60. Menendez KP, Mondal SK, McQuestion MJ, et al. (2006) Women's decision-making autonomy and dietary intake in Jharkhand State, India. https://apha.confex.com/apha/134am/techprogram/paper_ 140244.htm.

61. Na M, Jennings L, Talegawkar S, et al. (2015) Association between women's empowerment and infant and child feeding practices in Sub-Saharan Africa: an analysis of Demographic and Health Surveys. Public Health Nutr 18, 3155-3165.

62. Alive \& Thrive (2010) IYCF Practices, Beliefs and Influences in the SNNP Region, Ethiopia. Addis Ababa, Ethiopia: Alive \& Thrive.

63. Mokori A (2012) Nutritional status, complementary feeding practices and feasible strategies to promote nutrition in returnee children aged 6-23 months in northern Uganda. S Afr J Clin Nutr 25, 173-179.

64. Basnet S, Sathian B, Malla K, et al. (2015) Reasons for early or late initiation of complementary feeding: a study in Pokhara. Am J Public Health Res 3, 69-75.

65. Lutter CK, Daelmans BM, de Onis M, et al. (2011) Undernutrition, poor feeding practices, and low coverage of key nutrition interventions. Pediatrics 128, e1418-e1427.

66. Gibson RS \& Ferguson EL (2008) An Interactive 24-bour Recall for Assessing the Adequacy of Iron and Zinc Intakes in Developing Countries. HarvestPlus Technical Monographs. Washington, DC: International Food Policy Research Institute (IFPRI), International Center for Tropical Agriculture (CIAT).

67. Ghuman SJ, Lee HJ \& Smith HL. (2002) Measurement of Women's Autonomy According to Women and Their Husbands: Results From Five Asian Countries. Population Studies Center Working Paper. Philadelphia, PA: University of Pennsylvania. 